UDC 313.1

LBC 67.410

\title{
THE GROUNDS AND PROCEDURE FOR MODIFICATION OR TERMINATION OF PRE-TRIAL AGREEMENT ON COOPERATION
}

\author{
Jamal J. Gadgiev \\ Volgograd State University, Volgograd, Russian Federation; \\ Central Investigation Department of the Investigative Committee of the Russian Federation \\ in the City of Moscow, Moscow, Russian Federation
}

Introduction: the competent and smart use in the criminal procedure of such a legal instrument in the fight against crime as a pre-trial cooperation agreement and its implementation is of considerable importance for fullscale criminal investigation. In addition, it facilitates the exposition and prevention of new crimes, the establishment of all persons who committed wrongful acts, the location of crime instruments or of stolen property. In this connection, the author of the study sets the aim to bring the most relevant and up-to-date proposals for regulating the grounds and procedural order for modification or termination of the pre-trial cooperation agreement.

Methods: the methodological framework for this study is a set of scientific methods, among which the main place is occupied by the methods of systematicity, analysis and the comparative law method.

Results: grounded in the work the author's standpoint is based on the law and practical application of the pre-trial cooperation agreement by the bodies of preliminary investigation. On the basis of the legal and comparative analysis of civil law and criminal procedure rules there is drawn the analogy between the characteristics required for the modification and termination of the agreement depending on the circumstances encountered in the implementation of the already concluded agreement on cooperation.

Conclusions: as a result of the research the author determined the algorithm of the modification or termination of the pre-trial cooperation agreement on certain grounds. It is established that the considered aspects will allow improving the efficacy of the pre-trial cooperation agreement in the criminal procedure with respecting the rights and legitimate interests of the persons interested in such a "deal".

Key words: pre-trial cooperation agreement, termination or modification of the agreement, prosecutor, accused, suspect, preliminary investigation bodies.

УДК 313.1

ББК. 67.410

\section{ОСНОВАНИЯ И ПОРЯДОК ИЗМЕНЕНИЯ ИЛИ ПРЕКРАЩЕНИЯ ДОСУДЕБНОГО СОГЛАШЕНИЯ О СОТРУДНИЧЕСТВЕ}

\author{
Джамал Джанбулатович Гаджиев \\ Волгоградский государственный университет, г. Волгоград, Российская Федерация; \\ Главное следственное управление Следственного комитета Российской Федерации по г. Москве, \\ г. Москва, Российская Федерация
}

Введение: грамотное и разумное применение в уголовном судопроизводстве такого правового инструмента в борьбе с преступностью, как досудебное соглашение о сотрудничестве и его реализация, имеет правные деяни, опред с чем автором в работе поставлена цель исследования - привести наиболее соответствующие и актуальные предложения для регламентирования оснований и процессуального порядка изменения или прекращения досудебного соглашения о сотрудничестве.
} 
Методы: методологическую основу данного исследования составляет совокупность методов научного познания, среди которых основное место занимают методы системности, анализа и сравнительно-правовой метод.

Результаты: обоснованная в работе авторская позиция опирается на законодательство и практику применения досудебного соглашения о сотрудничестве органами предварительного следствия. На основании правового и сравнительного анализа гражданско-правовых и уголовно-процессуальных норм проводится аналогия характерных признаков, необходимых для изменения и расторжения соглашения в зависимости от обстоятельств, возникших в процессе реализации уже заключенного соглашения о сотрудничестве.

Выводы: в результате исследования автором определен алгоритм изменения или прекращения досудебного соглашения о сотрудничестве по определенным основаниям. Установлено, что рассматриваемые аспекты позволят повысить эффективность применения досудебного соглашения о сотрудничестве в уголовном судопроизводстве с соблюдением прав и законных интересов заинтересованных в такой «сделке» лиц.

Ключевые слова: досудебное соглашение о сотрудничестве, прекращение или изменение соглашения, прокурор, обвиняемый, подозреваемый, органы предварительного расследования.

\section{Введение}

После заключения любого договора могут возникнуть различные обстоятельства, требующие пересмотра его условий, то есть их изменения, дополнения или даже прекращения его действия путем расторжения. Эти обстоятельства могут быть вызваны разного рода причинами: поведением самих участников договора в силу несоблюдения его условий, наступлением событий, не зависящих от сторон, влияющих на ход реализации договора.

Изменение договора, как правило, означает, что при сохранении его силы в целом те или иные условия (отдельные из них), в том числе связанные с реализацией договорных обязанностей, выражаются по-новому [1]. При этом важно понимать, что изменить или расторгнуть можно только такой договор (сделку или соглашение), который признается на тот момент заключенным и действительным.

\section{Правовое регулирование применения досудебного соглашения в уголовном судопроизводстве}

Досудебное соглашение о сотрудничестве как любой договор в связи с наступлением определенных условий или обстоятельств также может быть изменен или прекращен при наличии для этого необходимых оснований.

Гражданско-правовое законодательство, регулируя договорные отношения, четко предусматривает правила изменения или расторжения договора ст. 450 Гражданского кодек- са Российской Федерации (далее - ГК РФ). Так, основанием для изменения договора может служить намерение одной из сторон договора при существенном нарушении договора другой стороной или в иных случаях, предусмотренных ГК РФ, другими законами или договором (ч. 2 ст. 450 ГК РФ) [3].

Относительно правового регулирования применения досудебного соглашения в уголовном судопроизводстве изначально нормы уголовно-процессуального законодательства не содержали каких-либо требований относительно вопросов изменения заключенного досудебного соглашения о сотрудничестве, что вызывало немало вопросов и создавало определенные трудности в его применении [6].

Только в июле 2016 г. в Уголовно-процессуальный кодекс РФ (далее - УПК РФ) были внесены изменения [6] относительно рассматриваемых нами аспектов, однако и они не в полной мере регулировали вопросы определения оснований изменения и прекращения досудебного соглашения о сотрудничестве и процедуры их реализации.

Так, статья 317.4 УПК РФ была дополнена ч. 5, согласно которой если подозреваемый или обвиняемый, с которыми заключено досудебное соглашение о сотрудничестве, сообщает лишь сведения о своем собственном участии в совершенном деянии, либо сведения, ставшие известными иным путем органам предварительного следствия, а также в случае отказа от дачи показаний, изобличающих других соучастников преступления, или выявления других данных, свидетельствующих о несоблюдении подозреваемым или обвиняемым условий и невыполнении ими обя- 
зательств, предусмотренных соглашением о сотрудничестве, прокурор вправе вынести постановление об изменении или о прекращении действия такого соглашения.

\section{Основания для изменения}

\section{или прекращения досудебного} соглашения о сотрудничестве

Исходя из положений данной нормы, а также проводя аналогию с практикой применения гражданско-правового договора, можно выделить следующие основания для изменения или прекращения досудебного соглашения о сотрудничестве:

- соглашение сторон;

- существенное нарушение или невыполнение условий досудебного соглашения о сотрудничестве подозреваемым или обвиняемым;

- в связи с существенным изменением обстоятельств;

- иные обстоятельства, предусмотренные законом или соглашением, в том числе отказ от его исполнения.

Рассмотрим каждое из перечисленных оснований подробнее:

1. Соглашение сторон. Это основание носит диспозитивный характер и по сути является самым «мирным» способом пересмотра условий соглашения или прекращения по нему отношений. Однако несмотря на то что визуально оформление данной процедуры кажется безобидным и весьма простым, обвиняемый (подозреваемый) должен понимать последствия принимаемых им решений. Поскольку прокурор, как сторона соглашения, не берет по нему на себя никаких обязательств, соответственно и изменить условия соглашения можно только касательно обязательств обвиняемого (подозреваемого). Поэтому инициатива в расторжении сотрудничества по данному основанию исходит, как правило, от стороны защиты путем подачи письменного ходатайства на имя прокурора, в котором должны быть указаны причины изменения условий соглашения или его прекращения, а также обязательства, которые обвиняемый согласен изменить или дополнить.

По этому основанию соглашение расторгается довольно легко, без проблем и конф- ликтов, поскольку в таком изменении или расторжении заинтересованы все стороны. Гораздо тяжелее расторжение соглашения о сотрудничестве происходит тогда, когда выгоду теряет лишь одна из сторон [2].

2. Существенное нарушение или невыполнение условий досудебного соглашения о сотрудничестве подозреваемым или обвиняемым.

В данном случае расторжение договора возможно также при согласии двух сторон или в случае того, если одна из сторон недовольна исполнением обязательств другой стороной в рамках заключенного ими соглашения о сотрудничестве. Здесь подразумевается не исполнение условий соглашения обвиняемым, а именно отказ последнего от исполнения обязательств, принятых по соглашению, или части из них.

При этом обвиняемый (подозреваемый), заявивший ходатайство о заключении досудебного соглашения о сотрудничестве, в случае отказа от дачи показаний в суде в отношении лиц, совершивших преступления, с учетом положений п. 2 ч. 4 ст. 46, п. 3 ч. 4 ст. 47 УПК РФ, должен понимать, что его показания могут быть использованы в качестве доказательств по уголовному делу; что на основании ст. 317.8 УПК РФ приговор может быть пересмотрен, если после назначения подсудимому наказания будет обнаружено, что он умышленно сообщил ложные сведения или умышленно скрыл от следствия какие-либо существенные сведения, им не соблюдены условия и не выполнены обязательства, предусмотренные досудебным соглашением о сотрудничестве; что после рассмотрения в порядке, предусмотренном ст. 317.7 УПК РФ, уголовного дела, выделенного в отдельное производство, он может быть привлечен к участию в уголовном деле в отношении соучастников преступления и иных лиц, совершивших преступления. Об этом ему разъясняется прокурором во время заключения соглашения о сотрудничестве (ч. 1 ст. 317.3 УПК РФ в ред. Федерального закона от 3 июля 2016 г. № 322-Ф3).

3. В связи с существенным изменением обстоятельств.

Существенное изменение обстоятельств, из сути которых исходили стороны 
сделки при ее заключении, выступает в качестве основания для изменения или прекращения правоотношений [5]. В законодательстве определено, что перемена факторов будет считаться значительной, когда произошли события, при которых, если бы участники могли предвидеть их, соглашение вообще не было бы ими подписано или возникло бы на иных условиях (ч. 1 ст. 451 ГК РФ).

По данному основанию инициатором изменения или расторжения соглашения о сотрудничестве может выступать любая из сторон: обвиняемый (подозреваемый) путем подачи ходатайства в порядке, рассмотренном выше; прокурор при получении советующей информации от следователя о существенном изменении обстоятельств, не позволяющих в достаточной мере реализовать заключенное соглашение, либо отпадении необходимости в сотрудничестве. Получив такие сведения, в целях принятия решения прокурор должен понимать причины модификации таких обстоятельств, их природу и характер, а также существенность внесений изменений или дополнений в заключенное соглашение о сотрудничестве и их последующее значение для уголовного дела. В связи с этим прокурор может запросить в порядке ст. 21 УПК РФ уголовное дело для ознакомления с ним либо получить информацию о процессе производства предварительного следствия от следователя, в том числе с приглашением обвиняемого.

Если компромисс между сторонами относительно приведения соглашения в соответствие со сложившимися условиями не достигнут, оно подлежит безоговорочному расторжению.

4. Иные обстоятельства, предусмотренные законом или соглашением, в том числе отказ от его исполнения.

Для реализации права одностороннего отказа от исполнения соглашения либо изменения его условий достаточно добровольного волеизъявления (устного или письменного) обвиняемого (подозреваемого). При этом последний не обязан объяснять причины такого решения, основываясь на положениях ст. 49 и ст. 51 Конституции РФ.

Отказ от исполнения условий соглашения может рассматриваться также как бездействие обвиняемого (подозреваемого) (от- каз от участия в следственных действиях, отказ от дачи показаний и т. д.). В таких случаях соглашение подлежит безоговорочному расторжению в любой момент уголовного судопроизводства по уголовному делу. В данном случае инициатором чаще всего выступает сторона обвинения.

В настоящее время невозможно сформулировать полный список причин, согласно которым соглашение о сотрудничестве может быть расторгнуто. Каждый договор о сотрудничестве индивидуален, в нем могут прописывать совершенно оригинальные и уникальные условия, вследствие несоблюдения которых договор может быть расторгнут.

Вне зависимости от оснований, рассмотренных нами выше при вынесении прокурором постановления об изменении досудебного соглашения о сотрудничестве, УПК РФ предусматривает составление нового досудебного соглашения о сотрудничестве. Но в таких случаях целесообразнее составлять соглашения об изменении (дополнительного соглашения), которые не влекут прекращения ранее заключенного досудебного соглашения, поскольку из указанных норм его судьба неясна. В случае же вынесения постановления о прекращении действия такого соглашения производство по уголовному делу осуществляется в общем порядке.

\section{Выводы}

На основании вышеизложенного можно сказать, что изменение или расторжение досудебного соглашения о сотрудничестве по собственной правовой природе можно считать сделкой, в которой принимают участие две стороны. Исходя из этого еще на стадии заключения досудебного соглашения о сотрудничестве и непосредственно в его тексте должны быть отражены обговоренные сторонами условия его возможного изменения (дополнения) или расторжения. А именно досудебное соглашение о сотрудничестве должно включать в себя раздел «Изменение или расторжение соглашения». В его содержании согласовываются условия и обстоятельства, при которых возможно изменение (дополнение) соглашения о сотрудничестве, в том числе и его прекращение [6]. 
Вместе с тем важно понимать, что заключение досудебного соглашения о сотрудничестве, его корректировка допускаются только в исключительных случаях, поскольку данный процесс требует определенных временных затрат, что может негативно отразиться на сроках предварительного расследования, то есть приведет к их затягиванию. К тому же изменение досудебного соглашения о сотрудничестве разрешено в тех случаях, если его прекращение противоречит публичным интересам, может повлиять на результаты расследования уголовного дела, а в последующем невынесение судом законного, обоснованного и справедливого решения.

\section{СПИСОК ЛИТЕРАТУРЫ}

1. Глебов, В. Г. Оценка эффективности применения в российском уголовном судопроизводстве досудебного соглашения о сотрудничестве / В. Г. Глебов, Н. С. Костенко, В. А. Ручкин // Вестник Волгоградской академии МВД России. - 2015. № 4 (35). - C. 96-100.

2. Миронец, Е. Е. Изменение и расторжение договора по гражданскому законодательству Российской Федерации : дис. ... канд. юрид. наук / Миронец Екатерина Евгеньевна. - Краснодар, 2002. $169 \mathrm{c}$.

3. Пугинский, Б. И. Гражданско-правовой договор / Б. И. Пугинский // Вестник МГУ. Серия 11, Право. -2002. - № 2. - С. 38-57.

4. Соколова, Г. А. Протокол разногласий к договору / Г. А. Соколова // Объединенная редакция деловых журналов. - Электрон. текстовые дан. - Режим доступа: http://www.ippnou.ru/article. php. - Загл. с экрана.

5. Тордия, И. В. Расторжение договора в связи с существенным изменением обстоятельств / И. В. Тордия // Вестник Тюменского государственного университета. Серия «Социально-экономические и правовые исследования». - 2011. № 3. - С. 154-158.

6. Федеральный закон «О внесении изменений в Уголовно-процессуальный кодекс Российской Федерации по вопросу совершенствования по- рядка судопроизводства при заключении досудебного соглашения о сотрудничестве» от 3 июля 2016 г. № 322-Ф3 // Собрание законодательства РФ. - 2016. 4 июля. - № 27 (ч. II). - Ст. 4255.

\section{REFERENCES}

1. Glebov V.G., Kostenko N.S., Ruchkin V.A. Otsenka effektivnosti primeneniya v rossiyskom ugolovnom sudoproizvodstve dosudebnogo soglasheniya o sotrudnichestve [Estimation of the Effectiveness of Pre-Trial Cooperation Contract in the Russian Criminal Trial]. Vestnik Volgogradskoy akademii MVD Rossii, 2015, no. 4 (35), pp. 96-100.

2. Mironets E.E. Izmenenie $i$ rastorzhenie dogovora po grazhdanskomu zakonodatelstvu Rossiyskoy Federatsii: dis. ... kand. yurid. nauk [Change and Termination of the Contract under Civil Law of the Russian Federation. Cand. jurid. sci. diss.]. Krasnodar, 2002. 169 p.

3. Puginskiy B.I. Grazhdansko-pravovoy dogovor [Civil Law Contract]. Vestnik MGU. Seriya 11, Pravo, 2002, no. 2, pp. 38-57.

4. Sokolova G.A. Protokol raznoglasiy k dogovoru [The Protocol of Disagreements to the Contract]. Obyedinennaya redaktsiya delovykh zhurnalov [Joint Edition of Business Journals]. URL: http://www.ippnou.ru/article.php.

5. Tordiya I.V. Rastorzhenie dogovora $\mathrm{v}$ svyazi s sushchestvennym izmeneniem obstoyatelstv [Termination of the Contract in Connection with a Significant Change in Circumstances]. Vestnik Tyumenskogo gosudarstvennogo universiteta. Seriya «Sotsialno-ekonomicheskie $i$ pravovye issledovaniya», 2011, no. 3, pp. 154-158.

6. Federalnyy zakon $« \mathrm{O}$ vnesenii izmeneniy v Ugolovno-protsessualnyy kodeks Rossiyskoy Federatsii po voprosu sovershenstvovaniya poryadka sudoproizvodstva pri zaklyuchenii dosudebnogo soglasheniya o sotrudnichestve» ot 3 iyulya $2016 \mathrm{~g}$. № 322-FZ [The Federal Law “On Amendments to the Code of Criminal Procedure of the Russian Federation on the Improvement of the Procedure for Judicial Proceedings in the Conclusion of a Pre-Trial Cooperation Agreement" of July 3, 2016 no. 322-FZ]. Sobranie zakonodatelstva RF, 2016, June 4, no. 27 (part II), art. 4255. 


\section{Information about the Author}

Jamal J. Gadgiev, Degree-Seeking Student, Department of Criminal Procedure and Criminalistics, Volgograd State University, Prosp. Universitetsky, 100, 400062 Volgograd, Russian Federation; Second Unit of the Office for Procedural Control, Central Investigation Department of the Investigative Committee of the Russian Federation in the City of Moscow, Arbat St., 16/2, bld. 1, 119002 Moscow, Russian Federation, Gadzhievproc@yandex.ru.

\section{Информация об авторе}

Джамал Джанбулатович Гаджиев, соискатель кафедры уголовного процесса и криминалистики, Волгоградский государственный университет, просп. Университетский, 100, 400062 г. Волгоград, Российская Федерация; второй отдел управления процессуального контроля, Главное следственное управление Следственного комитета Российской Федерации по г. Москве, ул. Арбат, 16/ 2, стр. 1, 119002 г. Москва, Российская Федерация, Gadzhievproc@yandex.ru. 